\title{
La picadura del pez araña
}

\author{
C. Boada Fernández del CAmpo, J. N. Lemus Reyes \\ Residente de Medicina de Familia y Comunitaria. Especialista \\ en Medicina Interna. C.S. La Laguna. Geneto
}

\section{Titulo en ingles}

\section{RESUMEN}

Presentamos el caso de un paciente picado por un pez araña (género Trachinus), frecuente en los mares templados del Atlántico, que evolucionó sin complicaciones. Describimos las características de este pez venenoso, las lesiones que produce, las complicaciones, tratamiento y prevención. En nuestro medio es preciso que el médico de Atención Primaria sepa reconocer y manejar adecuadamente la picadura del pez araña, de consecuencias ocasionalmente graves.

Palabras clave: Pez araña. Trachinus. Picaduras. Animales venenosos.

\begin{abstract}
We present the case of a patient stung by a weeverfish (gen Trachinus), frequent in Atlantic warm seas, who evolved whitout complications. We describe the characteristics of these venomous fish, the injury caused by it, its complications, and its management and prevention. The Primare Health Care physician in our setting, must be able to recognize and manage the weeverfish stinging, because of its occasionaly severe results.
\end{abstract}

Key words: Weeverfish. Trachinus. Stings. Venomous animals.

\section{INTRODUCCIÓN}

En un país con abundantes costas, los accidentes marinos son necesariamente frecuentes. Entre los producidos por peces se encuentran las mordeduras, descargas eléctricas, inoculación de veneno a través de sus espinas (ictioacantotoxismo) o la intoxicación por la ingestión de su carne. Exponemos un caso de ictioacantotoxismo por pez araña que, además de relativamente frecuente en nuestro medio, resulta representativo del tipo de manejo que requiere este tipo de accidente.

\section{OBSERVACIÓN CLÍNICA}

El paciente es un hombre de 57 años de edad, tornero de profesión, aficionado a la pesca, con antecedentes de ulcus péptico y de prostatitis crónica, sin hábitos tóxicos y buen estado de salud general.
Al intentar liberar de su anzuelo a un pez araña de unos $20 \mathrm{~cm}$ de longitud, resultó herido por las espinas de este (Fig. 1) en ambos dedos índices, donde se apreciaban sendas lesiones circulares de 2-3 mm de diámetro. Inmediatamente sintió un dolor muy vivo, insoportable, en el lugar de las heridas, además de malestar epigástrico, náuseas, sudoración generalizada y sensación de inminente pérdida de consciencia. En los minutos siguientes mejoró de los síntomas acompañantes y se agudizó el dolor, extendiéndose proximalmente hasta la mano, por lo que acudió a un servicio de urgencias. Se le trató con limpieza de la herida, aplicación de frío local, analgésico intramuscular y profilaxis antitetánica, remitiéndolo al médico de cabecera. La tensión arterial, temperatura y frecuencia cardiaca fueron normales. Al día siguiente, visto en nuestra consulta, se apreciaban las lesiones punzantes descritas, con fondo necrótico, y edema pálido y firme de los dedos afectados; el dolor per- 


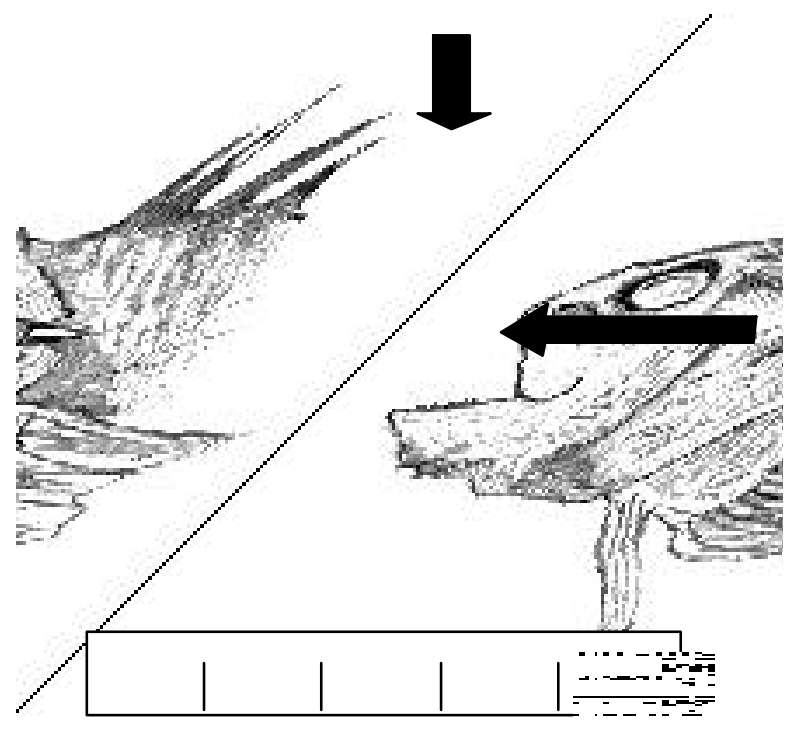

Figura 1

En esta ilustración del animal causante de la lesión en nuestro paciente, pueden obsevarse las espinas responsables de la inoculación del veneno

sistía en intensidad moderada, presentando además disestesia al tacto en la zona perilesional. Se le indicó prednisona, $15 \mathrm{mg}$ cada 12 horas, vía oral. Cuatro días después se había reducido el edema y el dolor, no presentaba signos inflamatorios ni fiebre y pudo incorporarse al trabajo, continuando con corticoides a mitad de la dosis anterior durante 3 días. Al mes, sólo tenía molestias locales muy ligeras.

\section{DISCUSIÓN}

Las heridas marinas producidas por un animal venenoso suelen dar lugar a un dolor lacerante, irradiado proximalmente, progresivo a lo largo de la $1^{\mathrm{a}}$ y $2^{\mathrm{a}}$ horas, de dos o tres días de duración, acompañado de otros síntomas sugestivos de un síndrome tóxico ${ }^{1}$, como sucedió en nuestro paciente. Las grandes laceraciones son típicas del aguijón de la pastinaca; las lesiones urticariales, exantemáticas y vesiculosas, de las medusas y el erizo de mar, acompañadas de tentáculos adheridos o espículas rotas; las lesiones punzantes pueden deberse a una variedad de animales (Tabla I) ${ }^{2}$. De todas formas, de las varias docenas de miles de especies de peces existentes, sólo unas 200 de ellas son venenosas y unas pocas potencialmente mortales ${ }^{3}$.

Se denomina pez araña (también araña blanca, araña de roca, pez víbora, escorpión, salvariego o faneca brava) a las cuatro especies del género Trachinus (T. draco, T. araneus, T. radiatus, $T$. vipera), familia traquínidos, orden perciformes; en inglés weeverfish, literalmente " pez dragón”. Todas son venenosas. Su picadura es conocida desde la antigüedad ${ }^{4}$. Su área de distribución comprende el Mediterráneo, Atlántico y Báltico, habitando en zonas arenosas y fangosas a menos de $100 \mathrm{~m}$ de profundidad, ascendiendo en verano cerca de la costa. Suele permanecer semienterrado en la arena, alimentándose de pequeños mariscos, cangrejos y peces. Su tamaño oscila entre los $15 \mathrm{~cm}$ (T. vipera) y los $50 \mathrm{~cm}$ (T. draco y $T$. araneus). Posee un cuerpo alargado y comprimido, hocico corto, boca grande y muy oblicua, ojos en la parte alta de la cabeza, primera aleta dorsal corta (con espinas venenosas), opérculo de cresta abultada terminada en un aguijón corto y robusto (igualmente venenoso) y escamas corporales dispuestas en series oblicuas abajo y atrás. Su carne es comestible y apreciada. Por su potencial acantotóxico (capacidad de inocular veneno a través de las espinas) se le agrupa con la escorpena, rascacio y cabracho (Scorpaena), pez piedra (Synanceja), pez león (Pterois) y pez sapo (Uranos-

\section{Tabla I}

\begin{tabular}{lll|}
\hline & & \\
& CARACTERÍSTICAS DE LAS LESIONES Y TRATAMIENTO INICIAL & \\
\hline Animal & Características de la herida & Primeras medidas \\
\hline Raya, pastinaca & Herida amplia, bordes cianóticos & Soporte vital \\
Erizo de mar & Punciones múltiples, patrón errático, & Extracción de espículas \\
fragmentos retenidos & con cinta adhesiva & Antídoto \\
Serpiente marina & 1 a 8 señales de dientes & Calor local, antídoto \\
Pez piedra & Halo eritematoso, edema precoz, & \\
Pulpo de anillos azules & dolor intenso & Soporte vital \\
Pez araña & Heridas indoloras, debilidad, parálisis & \\
& dificultad respiratoria & Calor local \\
\hline
\end{tabular}


copus $)^{2,5}$.

Las glándulas productoras del veneno se encuentran en relación con las espinas de la primera aleta dorsal y el aguijón del opérculo, en cuyos finos canalículos, cubiertos de tegumento, discurre el tóxico. La penetración de las espinas o el aguijón en la víctima determina la rotura de la cubierta tegumentaria y la inoculación de la toxina. Ésta es un polipéptido sensible a la tripsina y al calor, de $105.000 \mathrm{~mol}$ de peso molecular $(T \text {. draco })^{6}$, o constituido por cuatro subunidades de 81.000 mol cada una (T. vipera). Su efecto es neurotóxico y principalmente citotóxico, aumentando la permeabilidad al potasio en las preparaciones de sistema nervioso y produciendo hiperexcitabilidad y convulsiones en la rana ${ }^{8}$. La dosis letal mínima en el raton es de 1,8 $\mathrm{mg} / \mathrm{g}$ de peso, conteniendo todo el aparato venenoso de un ejemplar de $T$. draco unos $300 \mathrm{~m}$ de toxina $^{6,7}$. El aparato venenoso es una defensa contra los depredadores, causando lesiones al hombre accidentalmente al pisar el pez en su medio natural o al manipularlo fuera del agua, lo que incluye entre las posibles víctimas a bañistas, submarinistas, pescadores deportivos, hombres de mar y cocineros. Los lugares comúnmente lesionados son las extremidades inferiores o superiores.

Además del dolor característico descrito arriba, en la zona de la picadura aparece prurito, vasoconstricción, edema perilesional progresivo y trastornos de la coloración, con palidez en el lugar de la picadura y cianosis distal. Suele acompañarse de trastornos de la sensibilidad local que persisten semanas o meses. Puede producirse compromiso vascular con necrosis superficial y profunda y ocasionalmente gangrena. Entre las manifestaciones generales agudas destacan mareo, cefalea, náuseas, vómitos, hipotensión, sudoración y calambres musculares. Raramente se dan parálisis muscular, arritmias, distrés respiratorio y colapso. Los excepcionales casos de muerte se han asociado a la desafortunada circunstancia de penetración intravascular del aparato venenoso ${ }^{1}$. Puede haber infección secundaria de la herida, favorecida por la retención de cuerpos extraños (restos tegumentarios, espinas rotas), especialmente preocupante en caso de compromiso vascular, localización intra o yuxtaarticular, formación de absceso profundo o de huésped inmunodeprimido. Los gérmenes más comunes en el medio marino son bacilos gramnegativos, móviles y halofílicos, como el género Vibrio.

La herida puede cicatrizar con granuloma y retracciones, especialmente si se infectó ${ }^{2}$.

El tratamiento principal para el dolor es el calor local. La aplicación de fomentos calientes o la inmersión de la parte afectada en agua muy caliente $\left(45^{\circ} \mathrm{C}\right.$ o la máxima temperatura que pueda tolerar el paciente sin inducir una lesión térmica) durante 30 minutos alivia el intenso dolor de este tipo de lesiones, dada la termolabilidad del veneno. En caso de reaparecer tras este lapso, puede prolongarse la aplicación otros 30 ó 60 minutos $^{1-3,5}$. No parece indicado el frío, aunque algunos autores lo aconsejan como medida inicial para localizar el tóxico por vasoconstricción ${ }^{1,3}$. En nuestro paciente fue un error no aplicar calor y la prolongada aplicación de frío pudo entorpecer una solución espontánea más rápida. En todo caso está contraindicado el torniquete y la incisión y succión de la herida con objeto de extraer el tóxico, ya que aumentan el riesgo de complicaciones vasculares y de infección. Está indicado el tratamiento con analgésicos (desde paracetamol hasta opiáceos) de forma inmediata y mantenidos durante 2 ó 3 días. También se emplea la infiltración lesional de anestésicos locales.

La limpieza de la herida comprende la irrigación de la misma con cualquier diluyente a mano (como agua de mar) y la retirada de restos tegumentarios o de espinas. Una vez limpia debe explorarse y desbridarse cuidadosamente en condiciones asépticas. Se hará radiografía en caso de sospecha de retención de fragmentos radioopacos. No se suturará la herida, para que cicatrice por segunda intención.

Los corticoides y antihistamínicos por vía sistémica ayudan a combatir el edema y el prurito. Los primeros estarían contraindicados en caso de sospecha de infección, siendo en general recomendados. En caso de espasmo muscular asociado se inyectará por vía intravenosa lenta $10 \mathrm{ml}$ de gluconato cálcico al $10 \%$, que puede repetirse a intervalos de 4 horas ${ }^{2,5}$.

Como en toda herida, se actualizará la profilaxis antitetánica. Sólo en los pacientes inmunocomprometidos o lesiones de riesgo se indicaría el uso de antibióticos, por vía parenteral: cefotaxima, ceftazidima, cefoperazona, cloranfenicol o aminoglucósidos y, por vía oral, ciprofloxacino, trimetropin sulfametoxazol $^{2}$ o amoxicilina -claculánico ${ }^{3}$

En caso de compromiso vascular regional severo se han obtenido buenos resultados con bloqueo anestésico (bupivacaína al 0,5\%) del plexo braquial por vía axilar, para lesiones de la extremidad superior, o epidural, para la inferior ${ }^{8}$.

El estado de colapso se tratará como una emergencia, con soporte cardiorrespiratorio. No existe antídoto contra el veneno del pez araña.

La picadura por este pez puede prevenirse con una marcha atenta en los suelos marinos arenosos, el uso de calzado adecuado en este medio, la manipulación cuidadosa del pez fuera del agua o el uso de guantes a prueba de espinas, incluso muerto el animal.

\section{CORRESPONDENCIA:}

Carlos Boada Fernández del Campo

Avda. República Argentina,

Urb. Poeta Manuel Verdugo, 36

38208 La Laguna, Santa Cruz de Tenerife. Canarias

e.mail cboada@comtf.es

Telf. 922315730 


\section{Bibliografía}

1. Sancho i Fuertes R. En: Galler Montes F, coord. Medicina subacuática e hiperbárica, $2^{\mathrm{a}}$ ed. Madrid: Instituto Social de la Marina; $1991 ; 418-20$.

2. Auerbach PS. Marine envenomations. N Engl J Med 1991; 325: 486-93.

3. Mateu Sancho J. El niño intoxicado. Barcelona: MC Ediciones 1995; 106-10.

4. Dioscórides. De materia médica II. $13^{\mathrm{a}} \mathrm{Ed}$. facsímil de la traducción de Andrés de Laguna, tomo I. Barcelona: MCA Creación y Realización, 1994; 131.

5. López-Vélez R, Valledor de Lozoya A. Animales pon- zoñosos en España: aspectos médicos. Formación Médica Continuada en Atención Primaria 1995; 2: 231-4.

6. Chhatwal I, Dreyer F. Biological properties of a crude venom extract from the greater weever fish Trachinus draco. Toxicon 1992; 30: 77-85.

7. Perriere C, Goudey-Perriere F, Petek F. Purification of a letal fraction from the venom of de weeverfish Trachinus vipera C.V. Toxicon 1988; 26: 1222-7.

8. Linares del Río F, García Pumarino MM, Herruezo Pérez A. Aplicación terapéutica de los bloqueos 